УДК 665.6/.7+66.018.8+66.086.4+66.084.8

СНИЖЕНИЕ КОРРОЗИОННОЙ АКТИВНОСТИ НЕФТЯНОГО

СЫРЬЯ ПОСРЕДСТВОМ ВОЛНОВЫХ ВОЗДЕЙСТВИЙ

\title{
REDUCTION OF CORROSIVENESS OF CRUDE OIL BY WAVE EFFECTS
}

\author{
Г.В. Власова, Н.А. Пивоварова, В.П. Руднев
}

Астраханский государственный технический университет, г. Астрахань, Российская Федерация

\section{Galina V. Vlasova, Nadezhda A. Pivovarova, Vitaliy P. Rudnev}

\section{Astrakhan State Technical University, Astrakhan, Russian Federation}

\section{e-mail: ranec2003@mail.ru}

Аннотация. В работе показана возможность использования волновой обработки нефтяного сырья в процессе транспортирования его по магистральным трубопроводам от мест добычи до потребителей с целью снижения его коррозионной активности за счет удаления хлористых солей. Представлены объекты исследования и методы, использованные для исследования. Приведены результаты исследования по влиянию воздействий постоянного магнитного поля и депрессорной присадки на степень обессоливания нефти.

Предложен способ, который позволяет снизить коррозионную активность нефти в десятки раз, тем самым продлевая срок службы промыслового технологического оборудования и магистральных трубопроводов.

Установлено, что в результате низкоэнергетической обработки постоянным магнитным полем, количество извлеченных хлористых солей из нефти увеличилось на 20 \% относительно значений для товарной нефти, 
предназначенной для транспортировки. Как следствие, площадь коррозионных поражений и коррозионная активность нефти понизились от $100 \%$ до $11 \%$ ( в 10 раз), что, в свою очередь, снижает риск разлива нефти в результате коррозионного воздействия сырья на подводный трубопровод и в целом продлевает срок эксплуатации промыслового оборудования.

Abstract. The paper shows the possibility of using wave processing of crude oil in the process of transporting it through main pipelines from production sites to consumers in order to reduce its corrosiveness by removing chloride salts. The objects of research and the methods used for the research are presented. The results of a study on the effect of a constant magnetic field and a depressant additive on the degree of oil desalination are presented.

A method is proposed that allows to reduce the corrosiveness of oil tenfold, thereby extending the service life of field processing equipment and main pipelines.

It was found that as a result of low-energy treatment with a constant magnetic field, the amount of extracted chloride salts from oil increased by $20 \%$ relative to the values for commercial oil intended for transportation. As a result, the area of corrosion damage and the corrosive activity of oil decreased from $100 \%$ to $11 \%$ ( $\approx 10$ times), which, in turn, reduces the risk of oil spills as a result of the corrosive effect of raw materials on the subsea pipeline and generally extends the service life of the field equipment.

Ключевые слова: нефть; магнитная обработка; коррозионная активность; хлористые соли; обезвоживание нефти

Keywords: oil; magnetic treatment; corrosiveness; chloride salts; oil dehydration 
Опыт нефтегазодобывающих компаний показывает, что освоение месторождений углеводородного сырья на суше и на море сопровождается непреднамеренным негативным воздействием на окружающую среду [1]. Среди источников такого воздействия выделяют аварийные и прочие несанкционированные разливы нефти при добыче и транспортировке, сбои в технологическом режиме работы оборудования нефте- и газоперерабатывающих заводов и т.д.

Большие потери углеводородного сырья происходят при его транспортировке различным транспортом, среди которого наиболее используемым видом в России является транспортировка по трубопроводам [2].

По данным Greenpeace, причиной около $97 \%$ всех аварий на нефтепроводах в России является коррозия труб, которая происходит из-за изношенности оборудования и неправильной эксплуатации [3].

По данным, собранным в исследовании [4], основными причинами разливов нефти при эксплуатации магистральных трубопроводов являются:

- подземная коррозия;

- брак строительно-монтажных работ;

- дефект трубы;

- механические повреждения;

- нарушение правил эксплуатации;

- внутренняя эрозия и коррозия;

- стихийные бедствия;

- дефект оборудования;

- прочие.

В исследовании [2] отмечено, что подавляющее большинство аварий (до 83 \%) является следствием коррозии труб. Также выявлено, что на рост числа аварий существенно влияет характер местности. Так, по опыту нефтепромыслов Западной Сибири 5,5 \% случаев аварий на нефтепроводах 
происходят при водных переходах, что можно объяснить коррозией металла труб под действием солей и кислот, растворенных в воде [5].

Наряду с этим, технологические добавки, введенные в углеводородное сырье на стадии добычи, могут оказывать негативное воздействие и на последующие стадии его подготовки, транспортировки и переработки. Так, например, в работе [6] авторами установлено заметное влияние природы и концентрации технологических добавок на дисперсную структуру нефтяных систем. А в [7] доказали, что взаимное влияние различных технологических добавок и природы углеводородного сырья может приводить к образованию отложений в трубопроводах и технологическом оборудовании и, как следствие, к значительному снижению эффективности всех процессов.

Опыт эксплуатации нефтегазопромыслового оборудования показывает, что в течение времени, исчисляемого от одного месяца до нескольких лет, на внутренней поверхности резервуаров образуются отложения веществ. Некоторые из них, взаимодействуя с металлической поверхностью резервуаров, вызывают ее коррозию. Но наибольшее количество повреждений нефтегазопромыслового оборудования происходит в результате коррозии, вызванной образованием солевых отложений $[8,9]$.

Как известно, в акватории Каспия на сегодняшний день открыто несколько различных по своей характеристике крупных многопластовых месторождений (Сарматское, Хвалынское, Ракушечное, имени В. Филановского, имени Ю. Корчагина), но пока введено в эксплуатацию только два нефтегазоконденсатных месторождений: имени Юрия Корчагина и имени Владимира Филановского, расположенных в северной части акватории Каспийского моря в 180-190 км от г. Астрахань [10].

Протяженность подводного трубопровода, установленного на месторождении имени Ю. Корчагина, составляет 58 км. Подводный трубопровод испытывает как внешнюю (действие солей и кислот, растворенных в воде), так и внутреннюю (действие вредных примесей в 
нефти) коррозионные нагрузки, вследствие чего сокращается период эксплуатации трубы, а также возрастает вероятность возникновения чрезвычайной ситуации в виде аварийного разлива нефти на море. Следовательно, для сохранения экосистемы Каспийского моря необходимо минимизировать риск разливов нефти, в том числе и из-за коррозийных процессов внутри нефтепровода.

В качестве объекта исследования выбрана товарная нефть месторождения имени Ю. Корчагина, соответствующая ГОСТ Р 51858 2020. Физико-химическая характеристика нефти представлена в таблице 1.

Таблица 1. Характеристика нефти месторождения им. Ю. Корчагина

\begin{tabular}{|l|c|}
\hline \multicolumn{1}{|c|}{ Показатель } & Значение \\
\hline Плотность при $20{ }^{\circ} \mathrm{C},{\text { кг } / \mathrm{m}^{3}}^{\prime}$ & 834 \\
\hline Содержание асфальтенов, $\%$ масс. & 0,05 \\
\hline Температура застывания, ${ }^{\circ} \mathrm{C}$ & минус 6 \\
\hline Количество хлористых солей, мг/дм ${ }^{3}$ & 21,9 \\
\hline Коррозионное воздействие на медную пластину, класс & $4 \mathrm{a}$ \\
\hline Оценка коррозионных поражений, $\%$ поверхности/балл & $100 / 1$ \\
\hline Средний диаметр частиц, нм & 191 \\
\hline
\end{tabular}

Одним из эффективных, экологичных и малозатратных способов изменения свойств нефти является волновая обработка: ультразвук и постоянное магнитное поле. Сущность этих способов заключается в преобразовании дисперсной системы нефти в соответствии с теорией нефтяных дисперсных систем (НДС) профессора 3.И. Сюняева $[11,12]$.

С целью определения эффективности воздействия магнитного поля на нефтяное сырье при постоянной линейной скорости потока через активный зазор магнитного туннеля для более глубокой очистки от хлористых солей были проведены лабораторные исследования.

На первом этапе работы оценивали эффективность процесса обезвоживания нефти посредством магнитного поля. Результаты исследования представлены в таблице 2. 
Таблица 2. Количество выделенной воды из нефти

\begin{tabular}{|c|c|c|c|c|c|}
\hline \multirow{2}{*}{\begin{tabular}{|c|c|c|} 
Показатель \\
\cline { 2 - 6 }
\end{tabular}} & \multicolumn{5}{|c|}{ Магнитная индукция, Тл } \\
\cline { 2 - 6 } & 0 & 0,05 & 0,1 & 0,15 & 0,2 \\
\hline Содержание воды, \% об. & 2,0 & 2,1 & 2,3 & 2,4 & 2,4 \\
\hline
\end{tabular}

Как видно из таблицы 2, благодаря изменению структуры НДС при магнитной обработке количество извлеченной воды, собранной в ловушке приемнике Дина-Старка, увеличивается. Следовательно, остаточное содержание в нефти снижается в среднем от $5 \%$ до $20 \%$.

Известно, что хлористые соли растворены в воде, которая образует с нефтью водонефтяную эмульсию. Вследствие магнитной обработки водонефтяные эмульсии разрушаются, происходит освобождение глобул воды из бронирующих оболочек, облегчается процесс вывода воды из нефти и, тем самым, снижается остаточное содержание хлористых солей в нефти.

Для подтверждения данного факта была проведена следующая серия экспериментов, результаты которой представлены на рисунке 1.

Исходя из полученных данных, можно сделать вывод, что магнитная обработка оказывает неоднозначное влияние на извлечение хлористых солей из нефти. Максимальный выход солей был после обработки нефти магнитным полем с индукцией 0,15 Тл и составил 26,5 мг/дм³ (это примерно $20 \%$ от исходного остаточного количества). При данном варианте обработки не только увеличивается количество выводимых хлористых солей, но и сокращается количество водных вытяжек, что говорит об интенсификации процесса обессоливания. 


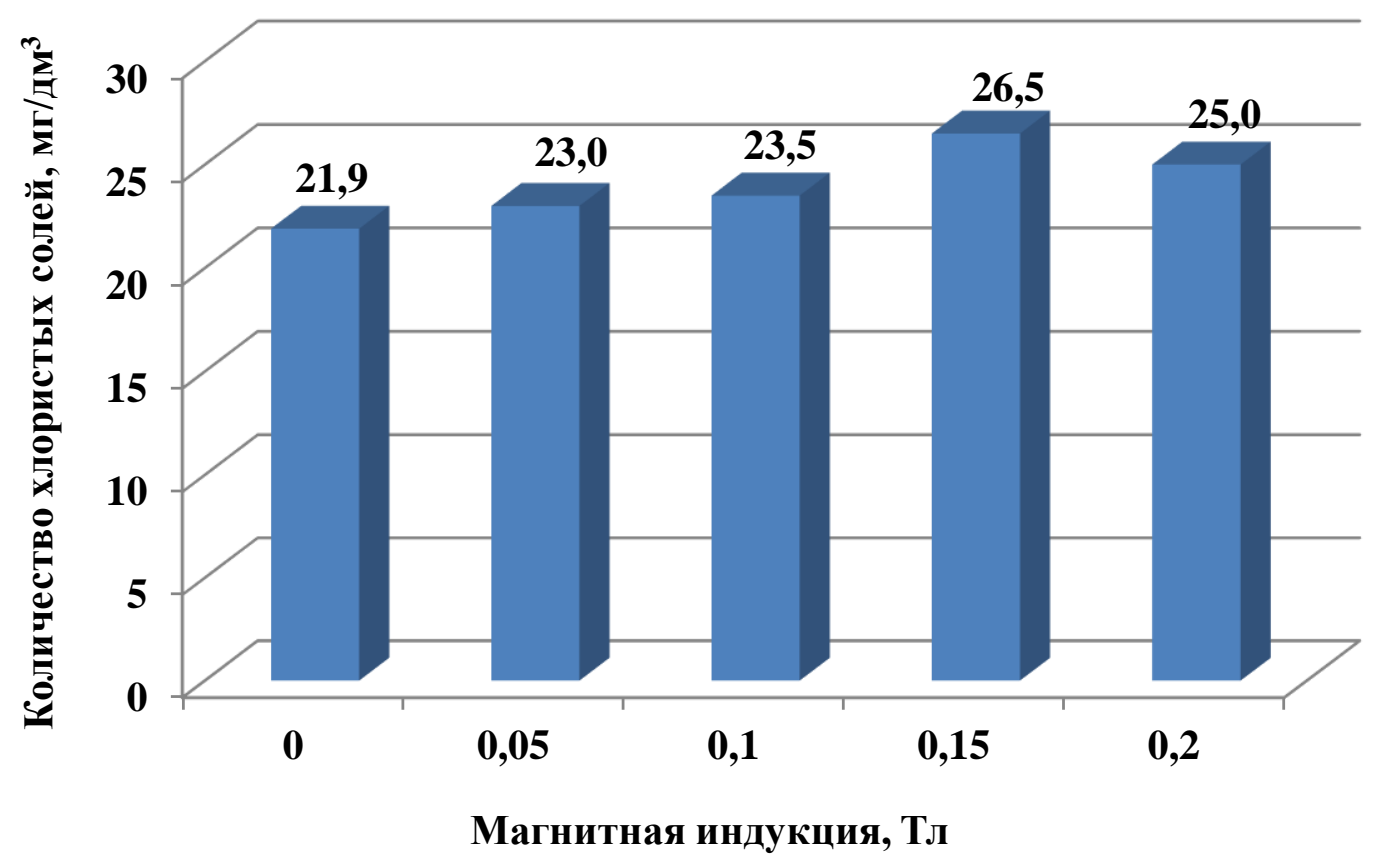

Рисунок 1. Зависимость количества извлечёных хлористых солей от магнитной индукции

Об улучшении процесса обессоливания нефтяного сырья посредством магнитной обработки говорит и степень доочистки от хлористых солей относительно значений, регламентируемых ГОСТ Р 51858-2020 для транспортировки нефти, значения которой представлены на рисунке 2.

Известно, что одним из наиболее значимых факторов устойчивости нефтяной дисперсной системы является средний диаметр частиц дисперсной фазы.

В связи с этим следующим этапом исследований стало определение изменения дисперсного состава товарной нефти месторождения имени Ю. Корчагина под действием магнитного поля.

Результаты исследования приведены в таблице 3. 


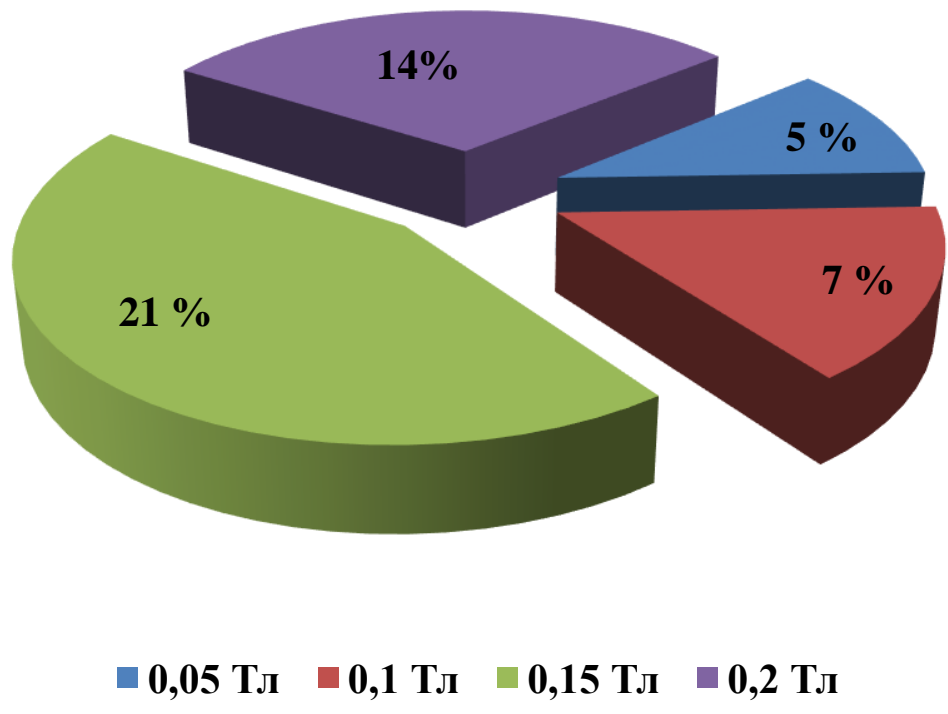

Рисунок 2. Зависимость степени доочистки нефтяного сырья от хлористых солей от магнитной индукции

Таблица 3. Изменение дисперсного состояния нефтяного сырья

\begin{tabular}{|l|c|}
\hline \multicolumn{1}{|c|}{ Вариант обработки } & $\begin{array}{c}\text { Средний диаметр частиц } \\
\text { дисперсной фазы, нм }\end{array}$ \\
\hline Без обработки & 191 \\
\hline Магнитная обработка 0,05 Тл & 178 \\
\hline Магнитная обработка 0,1 Тл & 177 \\
\hline Магнитная обработка 0,15 Тл & 179 \\
\hline Магнитная обработка 0,2 Тл & 175 \\
\hline
\end{tabular}

Как видно из таблицы 3, в результате увеличения магнитной индукции уменьшается диаметр частиц дисперсной фазы на 20 нм. Это говорит о том, что увеличивается дисперсность нефтяной системы и, как следствие, её гомогенность, и снижается вязкость, что способствует коалесценции глобул остаточной воды с растворенными в них хлористыми солями.

Предложенный вариант обработки постоянным магнитным полем позволил достичь степени доочистки нефти от хлористых солей $20 \%$. Следовательно, можно предположить, что коррозионная активность нефти тоже должна снизиться в несколько раз.

Для подтверждения этого предположения была проведена оценка коррозионной агрессивности нефти по ГОСТ 32329-2013 «Нефтепродукты. 
Определение коррозионного воздействия на медную пластинку» по эталону АСТМ для определения коррозии медной пластинки.

Предварительно подготовленные медные пластины поместили в емкости с пробами нефти:

1 образец - товарная нефть для транспортировки;

2 образец - товарная нефть, обработанная магнитным полем 0,15 Тл;

3 образец - товарная нефть, обработанная магнитным полем 0,15 Тл с добавлением депрессорной присадки Пральт-16 в количестве 5 г/т.

Испытания проводили в течение месяца при комнатной температуре $\left(23{ }^{\circ} \mathrm{C}\right)$.

Результаты исследования представлены на рисунке 3 и в таблице 4.

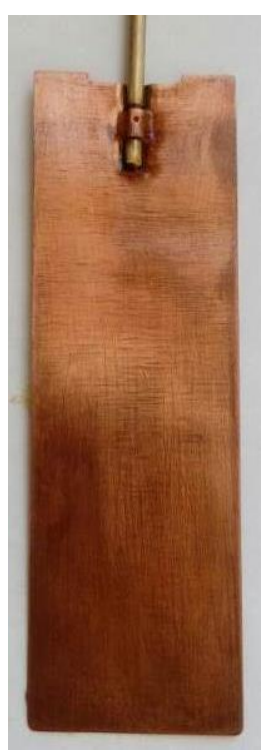

a)

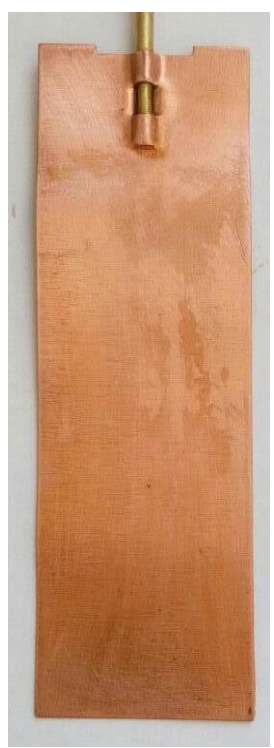

б)

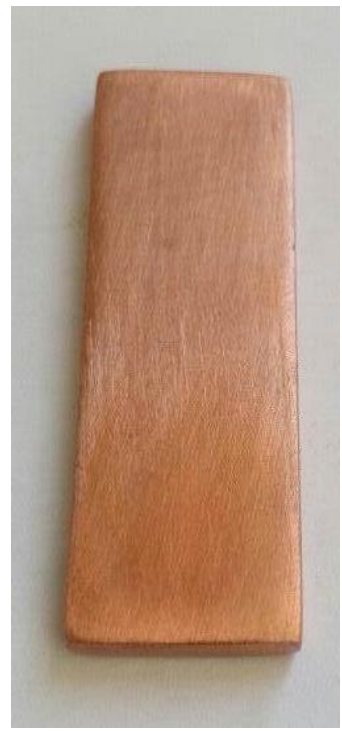

B)

a) товарная нефть;

б) нефть, обработанная магнитным полем 0,15 Тл;

в) нефть, обработанная магнитным полем 0,15 Тл

с добавлением депрессорной присадки в количестве 5 г/т

Рисунок 3. Зависимость коррозионной активности нефтяного сырья от различных внешних воздействий 
Таблица 4. Коррозионная активность проб по ГОСТ 32329-2013

\begin{tabular}{|c|c|c|c|c|}
\hline Описание пробы & $\begin{array}{c}\text { Класс } \\
\text { по ГОСТ }\end{array}$ & $\begin{array}{l}\text { Описание } \\
\text { состояния }\end{array}$ & $\begin{array}{l}\text { Описание } \\
\text { пластины }\end{array}$ & Описание эталона \\
\hline $\begin{array}{l}\text { Товарная нефть } \\
\text { для транспортировки }\end{array}$ & 4 a) & коррозия & темно-серый & $\begin{array}{l}\text { Прозрачно-черный, } \\
\text { темно-серый или } \\
\text { коричневый с едва } \\
\text { заметным } \\
\text { переливчато- } \\
\text { зеленым цветом. }\end{array}$ \\
\hline $\begin{array}{l}\text { Товарная нефть, } \\
\text { обработанная } \\
\text { магнитным полем } \\
0,15 \text { Тл }\end{array}$ & $1 \mathrm{~b})$ & $\begin{array}{c}\text { легкое } \\
\text { потускнение }\end{array}$ & $\begin{array}{c}\text { темно- } \\
\text { оранжевый }\end{array}$ & Темно-оранжевый. \\
\hline $\begin{array}{l}\text { Товарная нефть, } \\
\text { обработанная } \\
\text { магнитным полем } \\
0,15 \text { Тл с добавлением } \\
\text { депрессорной присадки } \\
\text { Пральт-16 } 5 \text { г/т }\end{array}$ & 1 a) & - & $\begin{array}{c}\text { светло- } \\
\text { оранжевый, } \\
\text { почти такой, как } \\
\text { свежеполирован- } \\
\text { ная пластинка }\end{array}$ & $\begin{array}{l}\text { Светло-оранжевый, } \\
\text { почти такой, как } \\
\text { свежеполированная } \\
\text { пластинка. }\end{array}$ \\
\hline
\end{tabular}

В таблице 5 приведены результаты оценки коррозионного поражения пластинок в соответствии с ГОСТ 9.311-87 «Единая система защиты от коррозии и старения. Покрытия металлические и неметаллические неорганические. Метод оценки коррозионных поражений».

Цвет продуктов коррозии на пластинах соответствовал окислообразным продуктам коррозии меди и сплавов на основе меди (темно-серый).

Таблица 5. Коррозионные изменения медных пластин по ГОСТ 9.311-87

\begin{tabular}{|l|c|c|}
\hline \multicolumn{1}{|c|}{ Описание пробы } & $\begin{array}{c}\text { Площадь } \\
\text { коррозионных } \\
\text { поражений, \% }\end{array}$ & $\begin{array}{c}\text { Оценочный балл } \\
\text { по ГОСТ 9.311- } \\
87\end{array}$ \\
\hline Товарная нефть для транспортировки & 100 & 1 \\
\hline $\begin{array}{l}\text { Товарная нефть, обработанная магнитным } \\
\text { полем 0,15 Тл }\end{array}$ & $5-11$ & 4 \\
\hline $\begin{array}{l}\text { Товарная нефть, обработанная магнитным } \\
\text { полем 0,15 Тл с добавлением депрессорной } \\
\text { присадки Пральт-16 5 г/т }\end{array}$ & $0-0,2$ & 9 \\
\hline
\end{tabular}

\section{Выводы}

В результате низкоэнергетической обработки постоянным магнитным полем, количество извлеченных хлористых солей из нефти увеличилось на $20 \%$ относительно значений для товарной нефти, предназначенной для 
транспортировки. Как следствие, площадь коррозионных поражений и коррозионная активность нефти понизилась от $100 \%$ до $11 \%$ ( $\approx$ в 10 раз), что, в свою очередь, снижает риск разлива нефти в результате коррозионного воздействия сырья на подводный трубопровод и в целом продлевает срок эксплуатации промыслового оборудования.

\section{Список используемых источников}

1. Мерчева В.С. Экологическая ответственность при разработке нефтегазовых месторождений Прикаспия // Астраханский вестник экологического образования. 2012. № 3 (21). С. 94-101.

2. Владимиров В.А., Дубнов П.Ю. Аварийные и другие несанкционированные разливы нефти // Стратегия гражданской защиты: проблемы и исследования. 2013. Т. 3. № 1 (4). С. 365-382.

3. Доклады Гринпис России по разливам нефти // Greenpeace Greenwire. URL: https://greenwire-russia.greenpeace.org/group/sokhranenie-klimata/post/ doklady-grinpis-rossii-po-razlivam-nefti (дата обращения: 04.04.2021).

4. Патин С.А. Нефтяные разливы и их воздействие на морскую среду и биоресурсы. М.: Всероссийский НИИ рыбного хозяйства и океанографии, 2008. $508 \mathrm{c}$.

5. Ибрагимов Н.Г., Хафизов А.Р., Шайдаков В.В. Осложнения в нефтедобыче. Уфа: ИНТЛ «Монография», 2003. 302 с.

6. Пивоварова Н.А., Кириллова Л.Б., Власова Г.В., Колосов В.М. Влияние технологических добавок на фазовое состояние газоконденсата // Стратегия объединения: решение актуальных задач нефтегазового и нефтехимического комплексов на современном этапе: матер. VII международ. промышл.-эконом. форума. М.: РГУ нефти и газа им. Губкина, 2014. C. $112-113$. 
7. Степанова Т.В., Гончаров В.М., Чернышева Е.А., Амиров Н.Н. Изменение физико-химических свойств нефтяного сырья в зависимости от остаточной концентрации реагентов, применяемых для нефтеотдачи пласта // Химическая технология. 2006. Т. 7. № 4. С. 11-16.

8. Ладенко А.А., Кунина П.С., Павленко П.П. Удаление асфальтосмолопарафиновых и минеральных отложений в оборудовании резервуарных парков // Газовая промышленность. 2010. № 3 (643). С. 69-72.

9. Сорокин С.А., Хавкин С.А. Особенности физико-химического механизма образования АСПО в скважинах // Бурение и нефть. 2007. № 10. C. 30-31.

10. Проекты роста // ЛУКОЙЛ. URL: http://www.lukoil.ru/Business/ Upstream/KeyProjects (дата обращения: 04.04.2021).

11. Пивоварова Н.А., Гражданцева А.С., Власова Г.В., Колосов В.М., Сальникова Т.В. Волновые технологии подготовки углеводородного сырья к первичной переработке // Нефть. Газ. Новации. 2018. № 5. С. 19-23.

12. Pivovarova N.A. Use of Wave Effect in Processing of the Hydrocarbonic Raw Material (Review) // Petroleum Chemistry. 2019. Vol. 59. P. 559-569. DOI: $10.1134 / \mathrm{S} 0965544119060148$.

\section{References}

1. Mercheva V.S. Ekologicheskaya otvetstvennost' pri razrabotke neftegazovykh mestorozhdenii Prikaspiya [Environmental Responsibility in the Development of Oil and Gas Fields in Caspian Sea Region]. Astrakhanskii vestnik ekologicheskogo obrazovaniya - Astrakhan Bulletin for Environmental Education, 2012, No. 3 (21), pp. 94-101. [in Russian].

2. Vladimirov V.A., Dubnov P.Yu. Avariinye i drugie nesanktsionirovannye razlivy nefti [Emergency and other Unauthorized Oil Spills]. Strategiya grazhdanskoi zashchity: problemy i issledovaniya - Civil Protection Strategy: Issues and Research, 2013, Vol. 3, No. 1 (4), pp. 365-382. [in Russian]. 
3. Doklady Grinpis Rossii po razlivam nefti [Greenpeace Russia Oil Spill Reports]. Greenpeace Greenwire. Available at: https://greenwirerussia.greenpeace.org/group/sokhranenie-klimata/post/doklady-grinpis-rossiipo-razlivam-nefti (accessed 04.04.2021). [in Russian].

4. Patin S.A. Neftyanye razlivy $i$ ikh vozdeistvie na morskuyu sredu $i$ bioresursy [Oil Spills and Their Impact on the Marine Environment and Living Resources]. Moscow, Vserossiiskii NII rybnogo khozyaistva i okeanografii Publ., 2008. 508 p. [in Russian].

5. Ibragimov N.G., Khafizov A.R., Shaidakov V.V. Oslozhneniya $v$ neftedobyche [Complications in Oil Production]. Ufa, INTL «Monografiya» Publ., 2003. 302 p. [in Russian].

6. Pivovarova N.A., Kirillova L.B., Vlasova G.V., Kolosov V.M. Vliyanie tekhnologicheskikh dobavok na fazovoe sostoyanie gazokondensata [Influence of Technological Additives on the Phase State of Gas Condensate]. Materialy VII Mezhdunarodnogo promyshlenno-ekonomicheskogo foruma «Strategiya ob"edineniya: reshenie aktual'nykh zadach neftegazovogo i neftekhimicheskogo kompleksov na sovremennom etape» [Materials of the VII International Industrial and Economic Forum «Strategy of Association: Solving Actual Problems of the Oil and Gas and Petrochemical Complexes at the Present Stage»]. Moscow, RGU nefti i gaza im. Gubkina Publ., 2014, pp. 112-113. [in Russian].

7. Stepanova T.V., Goncharov V.M., Chernysheva E.A., Amirov N.N. Izmenenie fiziko-khimicheskikh svoistv neftyanogo syr'ya $v$ zavisimosti ot ostatochnoi kontsentratsii reagentov, primenyaemykh dlya nefteotdachi plasta [Changes in the Physical and Chemical Properties of Crude Oil Depending on the Residual Concentration of Reagents Used for Oil Recovery]. Khimicheskaya tekhnologiya - Chemical Technology, 2006, Vol. 7, No. 4, pp. 11-16. [in Russian]. 
8. Ladenko A.A., Kunina P.S., Pavlenko P.P. Udalenie asfal'tosmoloparafinovykh i mineral'nykh otlozhenii $\quad \mathrm{v}$ oborudovanii rezervuarnykh parkov [Removal of Asphalt-Resin-Paraffin and Mineral Deposits in the Equipment of Tank Farms]. Gazovaya promyshlennost' - GAS Industry of Russia, 2010, No. 3 (643), pp. 69-72. [in Russian].

9. Sorokin S.A., Khavkin S.A. Osobennosti fiziko-khimicheskogo mekhanizma obrazovaniya ASPO v skvazhinakh [Physical and Chemical Mechanism of Production Asphalted, Resinous and of Paraffin Formations in the Wells]. Burenie i neft' - Drilling and Oil, 2007, No. 10, pp. 30-31. [in Russian].

10. Proekty rosta [Growth Projects]. LUKOIL. Available at: http://www.lukoil.ru/Business/Upstream/KeyProjects (accessed 04.04.2021). [in Russian].

11. Pivovarova N.A., Grazhdantseva A.S., Vlasova G.V., Kolosov V.M., Sal'nikova T.V. Volnovye tekhnologii podgotovki uglevodorodnogo syr'ya k pervichnoi pererabotke [Wave Techniques in Hydrocarbons Treatment Upstream Initial Processing]. Neft'. Gaz. Novatsii - Oil. Gaz. Novation, 2018, No. 5, pp. 19-23. [in Russian].

12. Pivovarova N.A. Use of Wave Effect in Processing of the Hydrocarbonic Raw Material (Review). Petroleum Chemistry, 2019, Vol. 59, pp. 559-569. DOI: 10.1134/S0965544119060148.

\section{Сведения об авторах}

\section{About the authors}

Власова Галина Владимировна, канд. техн. наук, доцент кафедры «Химическая технология переработки нефти и газа», АГТУ, г. Астрахань, Российская Федерация

Galina V. Vlasova, Candidate of Engineering Sciences, Assistant Professor of Chemical Technology of Oil and Gas Department, Astrakhan State Technical University, Astrakhan, Russian Federation

e-mail: xtng_vlasova@mail.ru 
Пивоварова Надежда Анатольевна, д-р техн. наук, профессор кафедры «Химическая технология переработки нефти и газа», АГТУ, г. Астрахань, Российская Федерация

Nadezhda A. Pivovarova, Doctor of Engineering Sciences, Professor of Chemical Technology of Oil and Gas Department, Astrakhan State Technical University, Astrakhan, Russian Federation

e-mail: nadpivov@live.ru

Руднев Виталий Петрович, д-р техн. наук, профессор кафедры «Химическая технология переработки нефти и газа», АГТУ, г. Астрахань, Российская Федерация

Vitaliy P. Rudnev, Doctor of Engineering Sciences, Professor of Chemical Technology of Oil and Gas Department, Astrakhan State Technical University, Astrakhan, Russian Federation 